\title{
Wake Island
}

National Cancer Institute

\section{Source}

National Cancer Institute. Wake Island. NCI Thesaurus. Code C123773.

An atoll in the North Pacific Ocean, between Hawaii and the Northern Mariana Islands. 